\title{
Neurogenic and non-neurogenic functions of endogenous neural stem cells
}

\author{
Erica Butti, Melania Cusimano, Marco Bacigaluppi * and Gianvito Martino* \\ Neuroimmunology Unit, Division of Neuroscience, Institute of Experimental Neurology, San Raffaele Scientific Institute, Milan, Italy
}

\section{Edited by:}

Luca Bonfanti, University of Turin, Italy

Reviewed by:

Joanne C. Conover, University of Connecticut, USA

Michael Chopp, Henry Ford Health System/Henry Ford Hospital, USA

\section{*Correspondence:}

Marco Bacigaluppi and Gianvito

Martino, Neuroimmunology Unit,

Division of Neuroscience, Institute

of Experimental Neurology, San

Raffaele Scientific Institute, Via

Olgettina 58, 20132 Milan, Italy

e-mail: bacigaluppi.marco@hsr.it;

martino.gianvito@hsr.it
Adult neurogenesis is a lifelong process that occurs in two main neurogenic niches of the brain, namely in the subventricular zone (SVZ) of the lateral ventricles and in the subgranular zone (SGZ) of the dentate gyrus (DG) in the hippocampus. In the 1960s, studies on adult neurogenesis have been hampered by the lack of established phenotypic markers. The precise tracing of neural stem/progenitor cells (NPCs) was therefore, not properly feasible. After the (partial) identification of those markers, it was the lack of specific tools that hindered a proper experimental elimination and tracing of those cells to demonstrate their terminal fate and commitment. Nowadays, irradiation, cytotoxic drugs as well as genetic tracing/ablation procedures have moved the field forward and increased our understanding of neurogenesis processes in both physiological and pathological conditions. Newly formed NPC progeny from the SVZ can replace granule cells in the olfactory bulbs of rodents, thus contributing to orchestrate sophisticated odor behavior. SGZ-derived new granule cells, instead, integrate within the DG where they play an essential role in memory functions. Furthermore, converging evidence claim that endogenous NPCs not only exert neurogenic functions, but might also have non-neurogenic homeostatic functions by the release of different types of neuroprotective molecules. Remarkably, these non-neurogenic homeostatic functions seem to be necessary, both in healthy and diseased conditions, for example for preventing or limiting tissue damage. In this review, we will discuss the neurogenic and the non-neurogenic functions of adult NPCs both in physiological and pathological conditions.

Keywords: neural stem cells, neurogenesis, inflammation, transplantation, germinal niches, bystander effect

\section{INTRODUCTION}

In 1913 Santiago Ramón y Cajal established that neurons of the brain are only generated during the neurodevelopmental phase, thus setting the so called "no new neurons" doctrine (Ramon Y Cajal, 1913). However, he soon reconsidered his conclusions when evaluating the results of an experiment performed a couple of years before by his younger assistant Francisco Tello. This experiment, in fact, showed that regenerating fibers growing from the stump of a transected optic nerve could suture with a "regenerating" peripheral sciatic nerve (Tello, 1907).

Nevertheless, despite this initial hint, the existence of dividing cells of neural origin in the central nervous system (CNS) was still debated (Hamilton, 1901; Allen, 1912) and could not be formally demonstrated until the beginning of the'60 when Smart (1961) and Altman (Altman and Das, 1965) demonstrated the effective presence of proliferating neural cells-i.e., neurogenesis-in the adult rodent brain. However, this finding would have been indisputably confirmed only 20 years later, namely when Fernando Nottebohm showed that neurogenesis in the ventricular zone is a phenomenon that normally occurs in intact adult female canaries (Nottebohm, 1981; Goldman and Nottebohm, 1983). Few years' later, adult neural stem/precursor cells (NPCs) were identified as a source of new neurons also in the brain of non-human primates and humans (Kukekov et al., 1999; Ming and Song, 2005). Later on, in vitro stable culturing systems either for rodent and human NPCs were established (Reynolds and Weiss, 1992).

Nowadays, we know that neurogenesis in the adult brain occurs in physiological conditions in specific neurogenic niches that have particular anatomical and functional characteristics. The role of neurogenesis after injury however still needs to be fully clarified. While there is substantial evidence that active, and latent, neurogenic niches might contribute to the formation of new cells upon CNS tissue damage, the precise role of these newly formed cells has not been yet completely understood. Here we review the possibility that endogenous NPCs exert functional roles not directly related to the production of new cells (the so called "non-neurogenic functions").

\section{NEUROGENESIS IN THE ADULT BRAIN: FROM CELLS TO FUNCTIONS \\ THE ADULT RODENT BRAIN}

Neurogenesis in the adult rodent brain occurs during adulthood in two main neurogenic niches, namely in the subgranular zone (SGZ) of the dentate gyrus (DG) in the hippocampus and in the subventricular zone (SVZ) of the lateral ventricles.

The SGZ is a thin layer of cells located between the two DG layers of granule and hilus cells. The primary role of SGZ is to generate new cells capable to functionally integrate within the 
DG granule layer. The DG granule layer is mainly composed by primary excitatory neurons supporting cognitive functions, such as memory and learning (Shors et al., 2002; Zhao et al., 2008). The development of granule cells from NPCs proceeds throughout different intermediate steps (Filippov et al., 2003). NPCs first develop into (i) radial astrocytes (i.e., type I cells) that, in turn, generate (ii) intermediate neural progenitors (i.e., type-D cells or type II progenitors) (Fukuda et al., 2003) — which are immature progenitors (also called neuroblasts) further differentiating into (iii) neuroblasts. Neuroblasts can be further sub divided into D1 (immature) and D2 (more differentiated) cells (i.e., type G or type III cells) (Filippov et al., 2003; Zhao et al., 2008), which progressively acquire electrophysiological characteristics of granule neurons. SGZ neurogenesis occurs in parallel to angiogenesis (Palmer et al., 2000) and endothelial cells act as scaffolding cells for NPCs. Therefore, endothelial cells provide signals and soluble factors that favor angiogenesis but also neurogenesis (Riquelme et al., 2008).

The second main neurogenic niche is the SVZ, a region located in the lateral side of the two lateral ventricles. This region originates from the neuroventricular epithelium of the embryonic ventricular zone, the area where radial glia proliferates during development. Similarly to the SGZ, the SVZ shows a rather heterogeneous population of stem and progenitor cells. Here we can find (i) relatively quiescent stem cells, known as B cells, that give rise to (ii) actively proliferating cells representing intermediate progenitors in transit to the terminal differentiation (i.e., type $\mathrm{C}$ cells or transit amplifying cells) (Doetsch et al., 1999). Type C cells differentiate into (iii) neuroblasts (i.e., immature type A cells) that migrate along the rostral migratory stream (RMS) toward the olfactory bulb $(\mathrm{OB})$ to give rise to new OB granule cells (Lois and Alvarez-Buylla, 1994; Belluzzi et al., 2003). The SVZ can be subdivided anatomically into three main structural domains: domain I (wall of the ventricle) contains ependymal cells as well as the primary cilium of type $\mathrm{B}$ cells and is in direct contact with the cerebrospinal fluid (CSF); domain II (below the wall of the ventricle) contains the cell bodies of type-B cells, type C cells, type A cells, neuronal terminals, and other supporting cells; domain III contains basal processes of B-cells that terminate in specialized end-feet capable of contacting blood vessels (Fuentealba et al., 2012). Due to their anatomical localization SVZ NPCs are strategically positioned within the brain: on the one hand, they are in direct contact with the CSF through their apical processes, and, on the other hand, they are tightly apposed to blood vessels forming a peculiar "periventricular" blood brain barrier (BBB) that is the barrier circumventing the lateral ventricles and the third and the fourth ventricle. SVZ NPCs are thus in close communication with two different peripheral blood-related microenvironments (Sawamoto et al., 2006; Mirzadeh et al., 2008; Tavazoie et al., 2008). It is still matter of debate whether the periventricular BBB is more permeable thus facilitating type $\mathrm{B}$ and $\mathrm{C}$ cells to receive blood-borne molecules regulating self-renewal and differentiation. Apart from the blood compartment, the SVZ is also located very close to crucial areas of the forebrain (i.e., basal ganglia, striatum) that contain GABAergic neurons capable of modulating interconnections between several cortical and sub-cortical brain areas (Koos and Tepper, 1999). In fact, NPCs in the SVZ are separated from the caudate nucleus and the striatum only by a layer of myelin and are in intimate contact with surrounding glia and blood vessels (Doetsch et al., 1999; Alvarez-Buylla and Lim, 2004). This peculiar position makes SVZ NPCs susceptible to the action of several neurotransmitters such as GABA (Platel et al., 2008, 2010), glutamate (Platel et al., 2010), ATP (Abbracchio et al., 2009), and acetylcholine (Cooper-Kuhn et al., 2004; Young et al., 2011), all neurotransmitters released from nearby neurons and collaterals. It is highly likely that SVZ NPCs can be directly influenced by the activity of neuronal networks (Tong et al., 2014). The decreased proliferation of NPCs, so far observed in Parkinson's disease, has been attributed to the loss of dopaminergic innervation of the SVZ (Curtis et al., 2007a). Postmortem studies in humans have identified dopaminergic fibers in contact with epidermal growth factor receptor (EGFR)- positive cells in the SVZ (Hoglinger et al., 2004). In addition, the SVZ area is innervated by serotoninergic fibers (Diaz et al., 2009) and serotonin has been documented to increase neurogenesis in the SVZ (Encinas et al., 2006; Kazanis, 2009).

\section{THE ADULT HUMAN BRAIN}

Although it has been variably shown that the two main neurogenic regions of the rodent brain, the SGZ and the SVZ, are also present in the adult human brain, human neurogenesis has some peculiarities that need to be highlighted.

In the 1990s, a study by Eriksson and colleagues performed in a group of cancer patients receiving the DNA labeling nucleotide Bromodeoxyuridine (BrdU) showed the BrdU signal in hippocampal neurons (Eriksson et al., 1998). This work formally established the presence of adult neurogenesis in the human hippocampus during adulthood. However, the observed neurogenesis could also have been attributed to the underlying pathology. Some years later Knoth et al. (2010) confirmed the presence of neurogenesis in the adult human hippocampus based on data obtained from 54 human autoptic specimens (age 0-100). In the same study, qualitative and quantitative age-related changesvery similar to those occurring in the rodent hippocampusfurther confirmed and expanded these findings (Knoth et al., 2010).

The human SVZ behaves, instead, very differently to the human adult hippocampus. In this region, the extent of this continuous neurogenesis as well as the presence of a RMS is still matter of debate. In 2004, Sanai and co-workers described within the SVZ a ribbon of proliferating astrocytes-lining the lateral ventricles of the adult human brain - that behaved as multipotent progenitor cells in vitro (Sanai et al., 2004). However, they did not find any evidence of chains of migrating neuroblasts in the SVZ or in close proximity to the OB (Sanai et al., 2007). After this provocative works, an intense debate occurred about the existence of a human RMS. In 2007, Curtis and colleagues showed histological evidence of a human RMS-like structure organized around a lateral ventricular extension reaching the $\mathrm{OB}$ (Curtis et al., 2007a,b; Sanai et al., 2007). Two successive reports challenged the existence of a RMS; only a ventromedial prefrontal cortex stream was observed in infants up to 2 years of age but not in adults (Sanai et al., 2011). More recently, a retrospective ${ }^{14} \mathrm{C}$ birth dating study showed that there is rather minimal adult 
neurogenesis in the human OB (Bergmann et al., 2012). While in the adult human brain 700 new neurons are added in each hippocampus per day (corresponding to an annual turnover of $1.75 \%$ of the neurons within the renewing fraction), OB neurons are as old as the individual since the decrease in neuroblast numbers in the SVZ and their migratory path suggested that there is negligible, if any, adult OB neurogenesis in humans (Spalding et al., 2013). It was concluded that less than $1 \%$ of the OB adult human neurons are exchanged over a century.

Therefore, while in the human brain the presence of neurogenic niches in the hippocampus and in the SVZ seems to be similar to other mammals, the precise function, role and fate of periventricular generated neuroblasts needs to be further refined.

\section{STUDYING THE ROLE OF ENDOGENOUS NPCs IN THE ADULT BRAIN}

While the study of neurogenesis was initially hampered by the technical limitation of tracing and labeling the dividing cells (Ming and Song, 2005), in the following years the major challenge became the inability to specifically ablate NPCs in a determined neurogenic niche. Consequently, approaches to eliminate proliferating cells, using either intracerebral administration of antimitotic drugs, such as Arabinofuranosyl Cytidine (AraC), or brain $\mathrm{x}$-rays irradiation, were developed (Doetsch et al., 1999; Monje et al., 2003) (Table 1). 60-90\% of proliferating cells within neurogenic niches can be successfully ablated by using the $\mathrm{x}$-rays irradiation method (Kageyama et al., 2012). However, there are still limitations due to the overt inflammatory reactions caused by the procedure (Palmer et al., 2000). These methods are however not selective for NPCs as also other proliferating cells (e.g., microglia, pericytes) might be affected by the treatment.

Recently, transgenic animals have been developed using various types of "marker" genes selectively expressed by NPCs or their progeny. Among transgenic models those based on the transgenic use of the thymidine kinase (TK) gene under the promoter of the GFAP (Garcia et al., 2004), Nestin (Singer et al., 2009), or Doublecortin (Jin et al., 2010) are the most used so far along with models in which the selective expression in NPCs of the diphtheria toxin fragment A (DT-A), under the neuron-specific enolase 2 gene promoter, has been achieved (Imayoshi et al., 2008). Another method to stop the proliferation of NPCs without direct ablation of the cells was the creation of conditional mouse models relying on the cre/flox system such ad the FoxJ1CreER:floxed K-Ras mouse. In this model, FoxJ1 positive cells (i.e., NPCs and ependymal cells in the CNS), upon administration of tamoxifen, are deleted for the Ras genes that are required for mitosis (Sabelström et al., 2013). Transgenic models are efficacious since $80-90 \%$ NPC ablation can be obtained; however, also in these models it is not possible to selectively analyse one or the other neurogenic niche. This can be resolved by using a model that has been recently published by our group and consists in a selective ablation of SVZ NPCs upon GCV administration due to the presence of the transgene only in the SVZ (Butti et al., 2012).

Finally, neurogenesis can be also studied in aged mice. In fact, in those mice a physiological decline of neurogenesis occurs both in the hippocampus and in the SVZ. Ageing does affect all tissues, but at the same time the decline of neurogenesis in this model is a naturally occurring process and therefore does not require a specific gene manipulation (Villeda et al., 2011).

\section{ROLE OF ENDOGENOUS NPCs IN PHYSIOLOGICAL CONDITIONS NEUROGENIC FUNCTIONS}

After having been a debated issue for years, it is now clear that hippocampal neurogenesis is a necessary process to preserve spatial memory, to support memory acquisition, especially in the early period of memory formation, (i.e., recent memory), and in the maintenance of the overall memory capacities (Snyder et al., 2005; Imayoshi et al., 2008). Sahay and colleagues showed that increased hippocampal neurogenesis-obtained in mice with the apoptosis-inducing gene Bax conditionally ablated from NPCs (i.e., Baxfl/fl Nes-CreERT2 mice) —was paralleled by an increased behavioral performance during a specific cognitive task where two similar contexts needed to be distinguished (Sahay et al., 2011). Kitamura and colleagues showed that hippocampal neurogenesis, particularly concerning the integration of new neurons, is a key factor in the gradual decay of DG

Table 1 | Newly developed mouse models to study the role of neurogenesis by specific ablation of different types of NPCs.

\begin{tabular}{llllll}
\hline $\begin{array}{l}\text { Mouse } \\
\text { model }\end{array}$ & $\begin{array}{l}\text { Target niche } \\
\text { and cells }\end{array}$ & Treatment & $\begin{array}{l}\text { Ablation } \\
\text { efficacy }\end{array}$ & $\begin{array}{l}\text { Experimental } \\
\text { model }\end{array}$ & References \\
\hline Nestin- $\delta$-HSV-TK-EGFP & SVZ and SGZ & 4 weeks of GCV & $\begin{array}{l}\approx 30 \% \text { in SVZ } \\
\approx 60 \% \text { in SGV }\end{array}$ & Distal MCAO & Sun et al., 2013 \\
FoxJ1-CreER; floxed K-Ras & Ependymal cells & 5 days of tamoxifen & $\approx 90 \%$ & Spinal cord injury & Sabelström et al., 2013 \\
Nestin-TK & SVZ & 4 weeks of GCV & $\approx 70 \%$ & Stroke and epilepsy & Butti et al., 2012 \\
Dcx-TK & SVZ and SGZ & 2 weeks of GCV & $\approx 80 \%$ & Permanent MCAO & Jin et al., 2010; Wang et al., 2012 \\
GFAP-TK & SGZ & $4-12$ weeks of GCV & $\approx 99 \%$ & Moderate stress diseases & Snyder et al., 2011 \\
Nestin-TK & SVZ and SGZ & 4 weeks of GCV & $\approx 90 \%$ & Study of neurogenesis & Singer et al., 2009 \\
Wt rats and mice & SGZ & X-ray irradiation & $\approx 85 \%$ & Study of hippocampal function & Kitamura et al., 2009 \\
Nes-CreERT2; & SVZ and SGZ & 4 days of tamoxifen & $\approx 30 \%$ & Study of olfactory bulbs & Imayoshi et al., 2008 \\
NSE-DTA & & & & &
\end{tabular}

Dcx, doublecortin; EGFP, enhanced green fluorescent protein; GCV, ganciclovir; GFAP, green fibrillary acidic protein; HSV, herpes simplex virus; MCAO, middle cerebral artery occlusion; NSE-DTA, neuron-specific enolase 2-diphtheria toxin fragment A; SVZ, subventricular zone; SGZ, subgranular zone; TK, thymidine kinase. 
long term potentiation (LTP) (Kitamura et al., 2009). They also showed that decreased neurogenesis is accompanied by a prolonged hippocampus-dependent period of associative fear memory: this mechanism has been proposed to play a role in clearing disused old memories to preserve the learning capacity of the hippocampus (Willshaw and Buckingham, 1990). Animals exposed to an environmental enrichment showed enhanced hippocampal neurogenesis (Kempermann et al., 1997).

The functional role of NPCs residing within the SVZ is certainly more controversial. As said before, newly formed NPCs in the rodent SVZ migrate along the RMS to the OB where they integrate as interneurons within the granule and glomerular cell layers; a process considered important in maintaining and reorganizing the OB system (Imayoshi et al., 2008). The integration of the new neurons in the OB and DG is varied: in the OB, neurogenesis contributes to the maintenance and reorganization of the whole system while in the DG new neurons are added to modulate and refine the existing neuronal circuits (Imayoshi et al., 2008). While SVZ neurogenesis in the adult brain seems not to exert a role in retaining the memory of spontaneous odor discrimination and innate olfactory preference (Imayoshi et al., 2008), it seems to be involved in consolidating long-lasting olfactory traces (Gheusi et al., 2000; Lazarini et al., 2009). Indeed, the increased survival of new-born granule cells observed after the enrichment is necessary for the increased inhibitory activity in the $\mathrm{OB}$ and leads to a better discrimination of highly similar odorants (Moreno et al., 2009). Recent studies have confirmed these data and assessed that while easy odor tasks (Mandairon et al., 2006) - e.g., the habituationdishabituation test-do not need neurogenesis (Kageyama et al., 2012), more difficult odor tasks, instead, do require modulation of the new-born neuron survival (Mandairon et al., 2006).

Besides the role in smell recognition, the instinctive response to pheromones is also processed by the main and accessory olfactory systems; SVZ neurogenesis plays an essential role in this context (Kageyama et al., 2012). For example, olfactory activities are very important for the maintenance of pregnancy (Bruce, 1959; Kaba et al., 1994): pregnancy induces biphasic stimulation of neurogenesis in the SVZ, leading to a biphasic increase in the production of both granule cells and periglomerular cells in the OB (Shingo et al., 2003). Neurogenesis in females is also induced by dominant male pheromones and seems to be important for sexual behaviors (Mak et al., 2007). Also in male, paternal-offspring recognition behaviors seem to rely on postnatal offspring interaction and are coupled to increased neurogenesis in the paternal OB and hippocampus (Mak and Weiss, 2010; Kageyama et al., 2012). Finally, SVZ neurogenesis might be required for predator avoidance and sex-specific responses that are olfaction dependent and innately programmed (Sakamoto et al., 2011).

\section{NON-NEUROGENIC FUNCTIONS}

In the last few years, other non-neurogenic functions of NPCs in the brain have been unraveled. NPCs are in fact able to produce and secrete a wide variety of factors that regulate and drive complex functions of the brain. A recent report showed that neuroblasts derived from both neurogenic niches (the SVZ and SGZ) exert a physiological phagocytic activity in clearing apoptotic neuronal precursors, and that this phagocytic activity is critically important in maintaining neurogenesis in the brain. Interestingly, NPC phagocytosis requires the intracellular engulfment protein ELMO1 to promote Rac activation downstream of phagocytic receptors (Lu et al., 2011).

Moreover, recent evidence supports the importance of nonneurogenic functions of NPCs. Sierra et al. demonstrated in fact that apoptotic new-born cells are rapidly cleared out through phagocytosis by unchallenged microglia present in the adult SGZ niche and that microglia is important in maintaining the homeostasis of the baseline neurogenic cascade (Sierra et al., 2010). Mosher et al. expanded this finding by demonstrating that NPCs are able, through the secretion of vascular endothelial growth factor (VEGF), to modulate microglial activation, proliferation and phagocytosis (Mosher et al., 2012). Furthermore, a bilateral crosstalk between NPCs and microglia seems to take place (Mosher et al., 2012).

Another "homeostatic" function coupled to NPCs has been recently described. Despite not having classical features of a neurogenic niche, median eminence tanycytes may also generate new-born neurons (Kokoeva et al., 2005; Lee et al., 2012). After a first study supporting the idea that hypothalamic neurogenesis in adult mice has a role in the control of energy-balance, including the capacity of regulating leptin-induced phosphorylation of signal transducer and activator of transcription 3 (STAT3) (Kokoeva et al., 2005), another recent work showed that median eminence tanycytes have a role in regulating the weight and metabolic activity of adult mice (Lee et al., 2012).

Moreover, newly generated neuroblasts residing within the SGZ seem to be able to dynamically regulate stress reactivity at both the endocrine and behavioral levels by buffering stress responses, through the regulation of the hypothalamicpituitary-adrenal axis (Snyder et al., 2011). In fact, neurogenesisdeficient mice also showed increased food avoidance after acute stress, increased behavioral despair in the forced swim test, and decreased sucrose preference, a measure of anhedonia (Snyder et al., 2011). It would be interesting to understand whether the observed alterations can be attributed to an alteration of median eminence tancytes (and vice versa), given that the models used for ablation of NPCs in this work did not exclusively target a single NPC subpopulation.

These data altogether support the concept that NPCs might exert, besides pure neurogenic functions, also a broad spectrum of "bystander" non-neurogenic functions aimed at maintaining the homeostasis of the brain (Figure 1) (Martino and Pluchino, 2006).

\section{ROLE OF ENDOGENOUS NPCS DURING CNS PATHOLOGY NEUROGENIC FUNCTIONS}

Different types of brain damage-such as stroke, epileptic seizures, trauma-induce the proliferation of NPCs in neurogenic areas, i.e., the SGZ and the SVZ (Riquelme et al., 2008). The majority of neurons formed in SGZ after an insult become dentate granule cells, similar to what occurs in the intact brain, while in the SVZ newly generated cells often migrate, away from the RMS, toward the lesion site (Jin et al., 2001).

Adult brain reacts to an ischemic injury by a long-lasting generation of neuroblasts from the SVZ; SDF-1a/CXCR4 signaling 

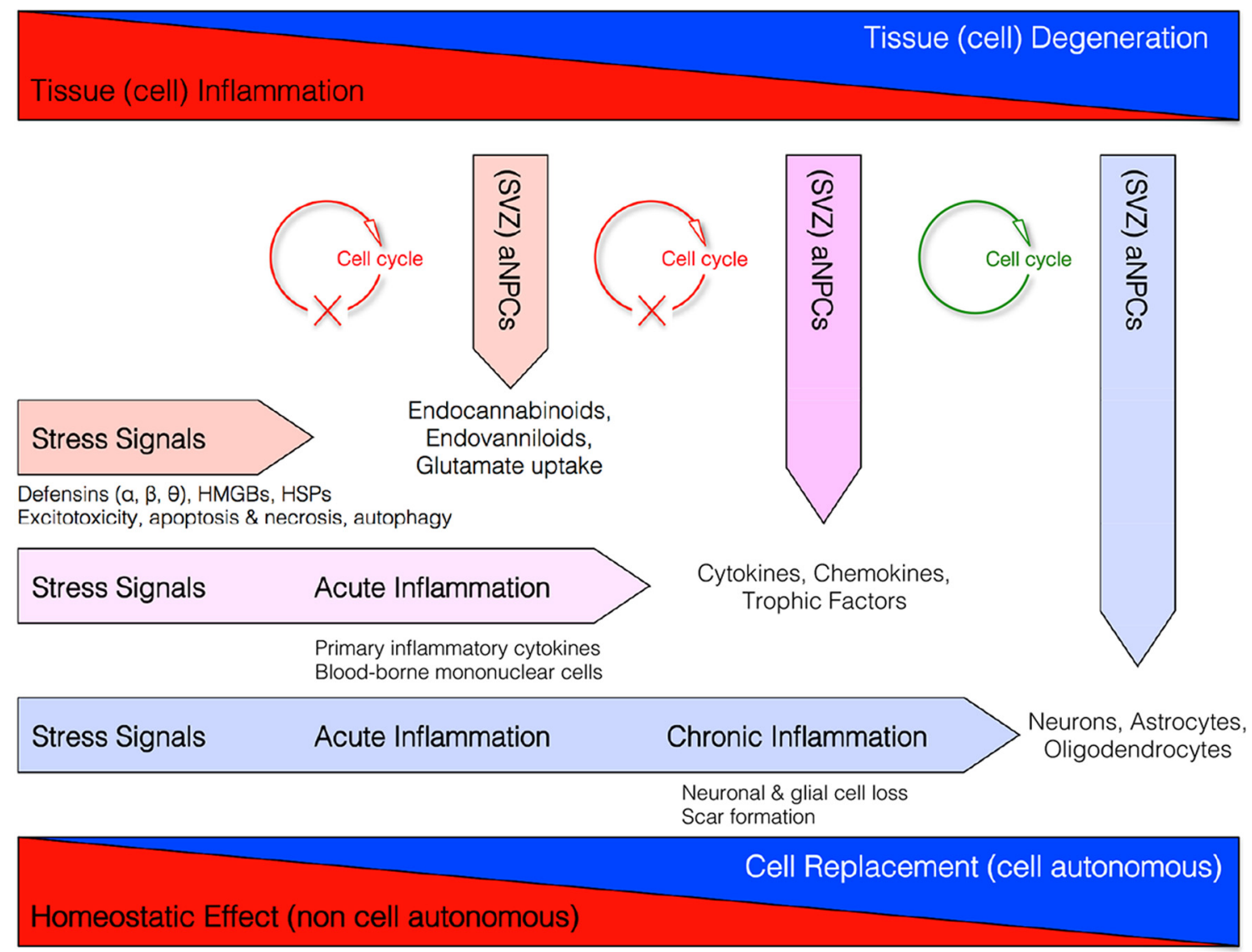

FIGURE 1 | Homeostatic multi-step actions exerted by endogenous NPCs: from maladaptive (stressful) conditions to pathological chronic tissue

damage. Endogenous NPCs adapt their homeostatic functions to the needs of the tissue. In order to reduce excitotoxicity so to prevent reactive inflammation, endogenous NPCs release neuroprotective molecules (i.e., endocannabinoids, endovanilloids) and increase glutamate uptake as soon as the occurrence of early stress signals. If this barrier fails and acute inflammation occurs, endogenous NPCs release different neuroprotective and anti-inflammatory molecules (e.g., cytokines, chemokines, and trophic factors) that, in turn, restrain the CNS infiltration of blood-borne inflammatory cells and the acute inflammatory reaction. This latter second-step process is also finalized to reduce the secondary tissue damage. Finally, during chronic inflammatory conditions when tissue architecture is already compromised, NPCs might differentiate into new cellular elements in order to replace endogenous cells lost. regulates the migration of new striatal neurons generated from endogenous NPCs toward the ischemic damage (Imitola et al., 2004). Within these newly formed peri-infarct neurovascular niches, newly-born immature neurons interact with the remodeling vasculature thanks to their production of stromal-derived factor 1 (SDF1) and angiopoietin 1 (Ang1) (Ohab et al., 2006). Interestingly neurogenesis and angiogenesis, another important reparative process taking place in the peri-ischemic tissue, are tightly coupled after stroke by VEGF that stimulates cell genesis (Teng et al., 2008).

A long-lasting neurogenic response reactive to ischemic injury has been observed not only in animal models but also in stroke patients (Marti-Fabregas et al., 2010). Interestingly, the enhanced neurogenic response is paralleled by increased microglia recruitment, probably due to a stroke-induced up regulation of CXCL10 in the SVZ; this chemokine might act as chemoattractant of CXCR3-expressing microglia (Rappert et al., 2004; Thored et al., 2009). About $80-90 \%$ of newly formed striatal neurons that potentially could replace the dead neurons will eventually die
(Arvidsson et al., 2002; Thored et al., 2006, 2007). In fact, only a small portion of SVZ-derived cells migrated into striatum does assume features of mature neurons with action potentials in a rodent model of ischemic stroke (Arvidsson et al., 2002).

Similarly to stroke, also epilepsy is associated with an increased level of progenitor proliferation paralleled with an accelerated maturation and integration of only few newly generated neurons (Rotheneichner et al., 2013). Neurons formed in the DG, after an epileptic insult, undergo caspase-mediated apoptotic death, similarly to NPCs isolated from the adult SVZ (Ekdahl et al., 2001). In animal models of epilepsy, the initial rise in neurogenesis is then followed by a long-lasting reduction of neurogenesis (Hattiangady et al., 2004). Reduced cell proliferation has been also observed in the hippocampus of children during the chronic phase of a frequent seizure convulsive disorder (Mathern et al., 2002; Rotheneichner et al., 2013). In experimental epilepsy, SVZ-derived cells migrate toward the hippocampus and differentiate terminally into glial but not neuronal cells (Parent et al., 2006). Newly born neurons might 
exacerbate chronically epileptic hippocampus if they aberrantly migrate and incorporate in the dentate hilus (Hattiangady and Shetty, 2008). Interestingly, inflammation might influence the functional integration of adult-born hippocampal neurons as a high degree of synaptic plasticity of the new neurons has been reported in an inflammatory environment. This effect seems to be finalized to counteract inflammation-induced increase of excitatory input (Jakubs et al., 2008). However, the extent to which seizure-induced neurogenesis might contribute to the formation of newly formed neurons destined to integrate into the damaged epileptic hippocampus still need to be clarified.

\section{NON-NEUROGENIC FUNCTIONS}

As said above, there is an increased reactive neurogenesis followed by a scarce integration of newly formed neurons into neuronal damaged circuits. This chain of events appears to be paradoxical. Several hypotheses have been proposed. One of these states that NPCs might exert tissue protective functions by deviating from their neuronal default into a glial differentiation pathway or remaining undifferentiated and secrete neuroprotective molecules in a bystander fashion.

Instead of differentiating into the neuronal default pattern, NPCs (from both SVZ and SGZ) may turn into both astroglial and oligodendroglial cells-a gliogenic rather than a neurogenic response-in order to constrain and/or prevent tissue damage. Several recent evidence supports this NPC-mediated phenomenon reacting to a CNS injury.

Localized photothrombotic/ischemic cortical injury triggers the production of BBB stabilizing astrocytes from the postnatal SVZ niche; an event controlled by the Notch modulator thrombospondin 4 (Thbs4). Indeed, knockout mice for Thbs 4 had a distorted neuroblast-astrocyte production, an abnormal glial scar formation, and a significant delayed increase of perilesional microvascular hemorrhages (Benner et al., 2013).

In demyelinating diseases, such as multiple sclerosis (MS), NPCs in the rodent SVZ niche become activated, upon demyelination, and provide a potential source of myelinating oligodendrocytes. SVZ-derived cells expand and migrate to the lesions, undergo oligodendrogenesis (Nait-Oumesmar et al., 1999), acquire morphology of myelinating cells, and express myelin proteins (Menn et al., 2006).

Using genetic fate mapping, it has been shown that, after a spinal cord injury (SCI), ependymal cells lining the central canal of the spinal cord have neurogenic potential. Indeed, in mice undergoing SCI, ependymal cell progeny starts migrating from the ependymal layer toward the injury site within 3 days after the injury; once within the lesion site, proliferating cells predominately differentiate into scar-forming astrocytes (Barnabe-Heider et al., 2010). In fact the glial scar that forms after SCI is composed by resident astrocytes and, in its central part, by ependymal cell-derived astrocytes (Barnabe-Heider et al., 2010). Ependymal cell-derived astrocytes might thus contribute to reinforce the injured spinal cord thus avoiding the expansion of the cystic cavity (Barnabe-Heider et al., 2010). Finally, cells recruited by the SCI not only produce scar-forming glial cells, but also, to a lesser degree, oligodendrocytes (Meletis et al., 2008).
The production of new neuronal or glial cells seems not to be the prevailing and sole mechanism of reactive neurogenesis occurring in response to tissue damage.

In stroke, not integrating newly formed SVZ-derived cells seem to protect from tissue injury through the secretion of neurotrophic factors (Jin et al., 2010; Wang et al., 2012; Sun et al., 2013). In a recent work SVZ NPCs were indeed shown to protect striatal neurons from glutamatergic excitotoxicity (as that occurring in the early phase of ischemic stroke and epilepsy) by releasing endogenous endocannabinoids (AEA and 2-AG) capable of binding to their specific receptors (CB1 and CB2) (Butti et al., 2012). Interestingly endovanilloids secreted by SVZ NPCs were found to suppress the growth of high-grade astrocytomas (HGA). NPCs by releasing endovanilloids activate the transient receptor potential vanilloid subfamily member-1 (TRPV1) on HGA cells that, in turn, triggers tumor cell death and prolongs overall survival time of the mice (Stock et al., 2012).

Also in another CNS injury model, SCI, scar stabilizing NPCderived astrocytes do not only restrict secondary enlargement of the lesion and further axonal loss (Sabelström et al., 2013), but also exert a non-neurogenic action via the secretion of growth factors acting as neuroprotectant to enhance the survival of neurons adjacent to the traumatic lesion.

As previously pointed out, whether a homeostatic function of the endogenous NPCs might occur, the SVZ zone seems to be the more appropriate area. In fact, as stated before, SVZ NPCs are in close communication with two different microenvironments being tightly apposed to blood vessels and in contact with the CSF, and also very close to crucial areas of the midbrain containing GABAergic neurons. A further confirmation of this working hypothesis came from a recent work showing that dendritic cell (DC) traffic within the CNS-from the choroid plexus to the cervical lymph nodes-along the RMS in order to modulate CNS-infiltrating regulatory $\mathrm{T}$ cell (Treg) function. This migration of DC seems to dampen experimental CNS auto-inflammatory diseases, thus suggesting that it ultimately prevents pathogenic T-cells from entering the CNS (Mohammad et al., 2014).

\section{NEUROGENIC vs. NON-NEUROGENIC FUNCTIONS}

Another important, but so far only partially solved issue, concerns how of NPCs can determine their fate between neurogenic and non-neurogenic functions in pathological conditions. The predominant view, supported by NPC transplantation studies, but confirmed to be valid also for endogenous NPCs as well, is that inflammation is in part responsible for the fate decision of newly formed NPCs.

Inflammation, as process occurring as a consequence of autoimmunity and/or traumatic and ischemic injuries, alter endogenous NPC proliferation and differentiation characteristics in a non-cell autonomous fashion (Pluchino et al., 2005). When inflammation fades away and neurodegeneration prevails, endogenous NPCs tend to differentiate into multiple neuronal lineages, depending on the situation, partially capable of integrating into damaged neuronal circuits (Kokaia et al., 2012).

However, in acute inflammatory conditions, while remaining undifferentiated, transplanted SVZ-derived NPCs might promote CNS tissue healing via the secretion of immunomodulatory 
and neuroprotective molecules, capable of reducing detrimental tissue responses. Instead, in chronic inflammatory conditions NPCs seem to be driven toward cell replacement (Martino and Pluchino, 2006).

\section{TRANSPLANTATION OF NPCs IN INFLAMMATORY CNS DISEASES}

As underlined before, NPC replacement-based studies allow to investigate the multimodal-neurogenic vs. non-neurogenic functions - mechanism of action of endogenous NPCs (Pluchino et al., 2005).

Whatever the therapeutic action exerted, transplanted NPCs show a certain degree of pathotropism toward inflammatory foci. This is due to the fact that such cells constitutively express an armamentarium of chemokines and chemokine receptors (e.g., CCR1, CCR5, CXCR3 and CXCR4), cell adhesion molecules (e.g., CD44) (Rampon et al., 2008) and integrins (e.g., VLA4) (Campos et al., 2004, 2006; Leone et al., 2008). Transplanted NPCs, very similarly to endogenous NPCs, have the characteristic to be able to follow and reach chemoattractant foci both when intraparenchymally and/or systemically injected (Ji et al., 2004; Pluchino et al., 2005).

When transplanted in acute or chronic inflammatory diseases (e.g., stroke, SCI, or MS), the majority of NPCs survive close to perivascular inflammatory foci (i.e., the atypical ectopic niche) where they interact with many other cell types such as CNS-infiltrating blood-borne inflammatory cells, endothelial cells and CNS-resident astrocytes and microglia. Within these ectopic niches, inflammatory molecules [e.g., interferon (IFN) $\gamma$, tumor necrosis factor $(\mathrm{TNF} \alpha)$ ] inhibit NPCs differentiation by blocking their cell cycle by up regulating the expression of cell cycle dependent kinase inhibitors (Pluchino et al., 2008). As undifferentiated cells, NPCs can produce a wide array of both secreted and transmembrane molecules which, in turn, exert both immunomodulatory and neurotrophic factors (Irvin et al., 2004; Pluchino et al., 2005; Seifert et al., 2005; Martino and Pluchino, 2006; Bacigaluppi et al., 2009; Cusimano et al., 2012).

In relapsing-remitting experimental autoimmune encephalomyelitis (EAE), the experimental model of MS, intravenously (i.v.) transplanted NPCs promote the apoptosis of encephalitogenic $\mathrm{T}$ cells either via the expression of death receptor ligands (for example, FasL, Trail and Apo3L) or the production of soluble mediators-i.e., NO synthase (iNOS), IFN $\gamma$-involved in mitochondrial-mediated apoptosis (Einstein et al., 2003, 2006; Pluchino et al., 2005). In the post-acute phase of ischemic or haemorrhagic stroke, i.v. transplantation of NPCs reduced activation of macrophage/microglia cells and CNS recruitment of blood-borne inflammatory cells (Lee et al., 2008; Bacigaluppi et al., 2009). Similarly, in the immediate time points following SCI, intrathecally (i.c.) as well as intralesionally transplanted NPCs modulate the local $\mathrm{T}$ cell, the microglial response (Ziv et al., 2006) and the recruitment of CNS infiltrating classically activated pro-inflammatory macrophages (Cusimano et al., 2012). Interestingly, it has been recently shown that also embryonic like induced pluripotent stem cell (iPSC)derived NPCs-once transplanted intrathecally into mice with EAE_-protect oligodendrocytes and OPCs from cell death. This transplantation promotes myelin tissue reconstruction via the selective production of leukemia inhibiting factor (LIF), and this production is guided by the inflammatory microenvironment (Laterza et al., 2013).

NPCs are therefore able to prevent inflammation-induced neuronal programmed cell death and glial scar formationoccurring, for example, in EAE, SCI, stroke-mainly via the paracrine secretion of the nerve growth factor (NGF), brainderived neurotrophic factor (BDNF), ciliary neurotrophic factor (CNTF), and glial-derived neurotrophic factor (GDNF) (Teng et al., 2002; Lu et al., 2003; Pluchino et al., 2003, 2005; Chu et al., 2004; Ryu et al., 2004; Ziv et al., 2006; Redmond et al., 2007; Bacigaluppi et al., 2009).

Another bystander effect exerted by transplanted NPCs is to directly modulate neuronal circuit plasticity (Zhang and Chopp, 2009). In an experimental model of ischemic stroke human foetal NPCs significantly improved functional outcomes by promoting neuronal dendritic arborization in both hemispheres and axonal projections within the corticostriatal and corticospinal pathways. These effects have been attributed to the capacity of transplanted NPCs to re-express developmental molecules such as guidance molecules (i.e., slit, thrombospondin 1 and 2) but also trophic factor such as VEGF (Andres et al., 2011).

\section{CONCLUSIONS}

NPCs in the adult brain exert an important homeostatic role either by producing new cells (neuronogenic or gliogenic function) or by orchestrating important processes (non-neurogenic functions): both actions are pivotal for the maintenance of the proper functioning of the CNS. Those neurogenic and nonneurogenic functions are in part NPC autonomous but are also driven by the microenvironment that might foster, according to the tissue needs, one of these functions. Our understanding of the complex interplay between neuronal, macroglial, and microglial cells in physiological and pathological conditions is continuously evolving, and we have now to consider NPCs as integral part of this interplay. New techniques of molecular biology and genetics will allow us to further understand the neurogenic vs. non-neurogenic functions of endogenous NPCs, and this knowledge would certainly help the scientific community to design efficacious stem cell-based treatment for still incurable neurological disorders.

\section{ACKNOWLEDGMENTS}

This work has been in part supported by the National Multiple Sclerosis Society (NMSS), Fondazione Italiana Sclerosi Multipla (FISM), MIUR Regione Lombardia (NetLips Project), ELA Foundation, TargetBrain (EU Framework 7 project HEALTH-F22012-279017) and NEUROKINE ITN network (EU project). We acknowledge the help of Dr. Stefano Sandrone.

\section{REFERENCES}

Abbracchio, M. P., Burnstock, G., Verkhratsky, A., and Zimmermann, H. (2009). Purinergic signalling in the nervous system: an overview. Trends Neurosci. 32, 19-29. doi: 10.1016/j.tins.2008.10.001

Allen, E. (1912). The cessation of mitosis in the central nervous system of albino rat. J. Comp. Neurol. 22, 547-568.

Altman, J., and Das, G. D. (1965). Autoradiographic and histological evidence of postnatal hippocampal neurogenesis in rats. J. Comp. Neurol. 124, 319-335. doi: $10.1002 /$ cne. 901240303 
Alvarez-Buylla, A., and Lim, D. A. (2004). For the long run: maintaining germinal niches in the adult brain. Neuron 41, 683-686. doi: 10.1016/S08966273(04)00111-4

Andres, R. H., Horie, N., Slikker, W., Keren-Gill, H., Zhan, K., Sun, G., et al. (2011). Human neural stem cells enhance structural plasticity and axonal transport in the ischaemic brain. Brain 134, 1777-1789. doi: 10.1093/brain/awr094

Arvidsson, A., Collin, T., Kirik, D., Kokaia, Z., and Lindvall, O. (2002). Neuronal replacement from endogenous precursors in the adult brain after stroke. Nat. Med. 8, 963-970. doi: 10.1038/nm747

Bacigaluppi, M., Pluchino, S., Peruzzotti-Jametti, L., Kilic, E., Kilic, U., Salani, G., et al. (2009). Delayed post-ischaemic neuroprotection following systemic neural stem cell transplantation involves multiple mechanisms. Brain 132, 2239-2251. doi: 10.1093/brain/awp174

Barnabe-Heider, F., Goritz, C., Sabelstrom, H., Takebayashi, H., Pfrieger, F. W., Meletis, K., et al. (2010). Origin of new glial cells in intact and injured adult spinal cord. Cell Stem Cell 7, 470-482. doi: 10.1016/j.stem.2010.07.014

Belluzzi, O., Benedusi, M., Ackman, J., and Loturco, J. J. (2003). Electrophysiological differentiation of new neurons in the olfactory bulb. J. Neurosci. 23, 10411-10418.

Benner, E. J., Luciano, D., Jo, R., Abdi, K., Paez-Gonzalez, P., Sheng, H., et al. (2013). Protective astrogenesis from the SVZ niche after injury is controlled by Notch modulator Thbs4. Nature 497, 369-373. doi: 10.1038/nature12069

Bergmann, O., Liebl, J., Bernard, S., Alkass, K., Yeung, M. S., Steier, P., et al. (2012). The age of olfactory bulb neurons in humans. Neuron 74, 634-639. doi: 10.1016/j.neuron.2012.03.030

Bruce, H. M. (1959). An exteroceptive block to pregnancy in the mouse. Nature 184, 105. doi: 10.1038/184105a0

Butti, E., Bacigaluppi, M., Rossi, S., Cambiaghi, M., Bari, M., Cebrian Silla, A., et al. (2012). Subventricular zone neural progenitors protect striatal neurons from glutamatergic excitotoxicity. Brain 135, 3320-3335. doi: 10.1093/brain/aws194

Campos, L. S., Decker, L., Taylor, V., and Skarnes, W. (2006). Notch, epidermal growth factor receptor, and betal-integrin pathways are coordinated in neural stem cells. J. Biol. Chem. 281, 5300-5309. doi: 10.1074/jbc.M511886200

Campos, L. S., Leone, D. P., Relvas, J. B., Brakebusch, C., Fassler, R., Suter, U., et al. (2004). Betal integrins activate a MAPK signalling pathway in neural stem cells that contributes to their maintenance. Development 131, 3433-3444. doi: 10.1242/dev.01199

Chu, K., Kim, M., Park, K. I., Jeong, S. W., Park, H. K., Jung, K. H., et al. (2004). Human neural stem cells improve sensorimotor deficits in the adult rat brain with experimental focal ischaemia. Brain Res. 1016, 145-153. doi: 10.1016/j.brainres.2004.04.038

Cooper-Kuhn, C. M., Winkler, J., and Kuhn, H. G. (2004). Decreased neurogenesis after cholinergic forebrain lesion in the adult rat. J. Neurosci. Res. 77, 155-165. doi: 10.1002/jnr.20116

Curtis, M. A., Eriksson, P. S., and Faull, R. L. (2007a). Progenitor cells and adult neurogenesis in neurodegenerative diseases and injuries of the basal ganglia. Clin. Exp. Pharmacol. Physiol. 34, 528-532. doi: 10.1111/j.14401681.2007.04609.x

Curtis, M. A., Kam, M., Nannmark, U., Anderson, M. F., Axell, M. Z., Wikkelso, C., et al. (2007b). Human neuroblasts migrate to the olfactory bulb via a lateral ventricular extension. Science 315, 1243-1249. doi: 10.1126/science.1136281

Cusimano, M., Biziato, D., Brambilla, E., Alfaro-Cervello, C., Snider, S., Donegà, M., et al. (2012). Transplanted NPCs instruct phagocytes to remodel the injured spinal cord tissue. Brain 135, 447-460. doi: 10.1093/brain/awr339

Diaz, D., Valero, J., Airado, C., Baltanas, F. C., Weruaga, E., and Alonso, J. R. (2009). Sexual dimorphic stages affect both proliferation and serotonergic innervation in the adult rostral migratory stream. Exp. Neurol. 216, 357-364. doi: 10.1016/j.expneurol.2008.12.013

Doetsch, F., Caille, I., Lim, D. A., Garcia-Verdugo, J. M., and Alvarez-Buylla, A. (1999). Subventricular zone astrocytes are neural stem cells in the adult mammalian brain. Cell 97, 703-716. doi: 10.1016/S0092-8674(00)80783-7

Einstein, O., Grigoriadis, N., Mizrachi-Kol, R., Reinhartz, E., Polyzoidou, E., Lavon, I., et al. (2006). Transplanted neural precursor cells reduce brain inflammation to attenuate chronic experimental autoimmune encephalomyelitis. Exp. Neurol. 198, 275-284. doi: 10.1016/j.expneurol.2005.11.007

Einstein, O., Karussis, D., Grigoriadis, N., Mizrachi-Kol, R., Reinhartz, E., Abramsky, O., et al. (2003). Intraventricular transplantation of neural precursor cell spheres attenuates acute experimental allergic encephalomyelitis. Mol. Cell. Neurosci. 24, 1074-1082. doi: 10.1016/j.mcn.2003.08.009
Ekdahl, C. T., Mohapel, P., Elmer, E., and Lindvall, O. (2001). Caspase inhibitors increase short-term survival of progenitor-cell progeny in the adult rat dentate gyrus following status epilepticus. Eur. J. Neurosci. 14, 937-945. doi: 10.1046/j.0953-816x.2001.01713.x

Encinas, J. M., Vaahtokari, A., and Enikolopov, G. (2006). Fluoxetine targets early progenitor cells in the adult brain. Proc. Natl. Acad. Sci. U.S.A. 103, 8233-8238. doi: 10.1073/pnas.0601992103

Eriksson, P. S., Perfilieva, E., Bjork-Eriksson, T., Alborn, A. M., Nordborg, C., Peterson, D. A., et al. (1998). Neurogenesis in the adult human hippocampus. Nat. Med. 4, 1313-1317. doi: 10.1038/3305

Filippov, V., Kronenberg, G., Pivneva, T., Reuter, K., Steiner, B., Wang, L. P., et al. (2003). Subpopulation of nestin-expressing progenitor cells in the adult murine hippocampus shows electrophysiological and morphological characteristics of astrocytes. Mol. Cell. Neurosci. 23, 373-382. doi: 10.1016/S1044-7431(03) 00060-5

Fuentealba, L. C., Obernier, K., and Alvarez-Buylla, A. (2012). Adult neural stem cells bridge their niche. Cell Stem Cell 10, 698-708. doi: 10.1016/j.stem.2012.05.012

Fukuda, S., Kato, F., Tozuka, Y., Yamaguchi, M., Miyamoto, Y., and Hisatsune, T. (2003). Two distinct subpopulations of nestin-positive cells in adult mouse dentate gyrus. J. Neurosci. 23, 9357-9366.

Garcia, A. D., Doan, N. B., Imura, T., Bush, T. G., and Sofroniew, M. V. (2004). GFAP-expressing progenitors are the principal source of constitutive neurogenesis in adult mouse forebrain. Nat. Neurosci. 7, 1233-1241. doi: 10.1038/nn1340

Gheusi, G., Cremer, H., McLean, H., Chazal, G., Vincent, J. D., and Lledo, P. M. (2000). Importance of newly generated neurons in the adult olfactory bulb for odor discrimination. Proc. Natl. Acad. Sci. U.S.A. 97, 1823-1828. doi: 10.1073/pnas.97.4.1823

Goldman, S. A., and Nottebohm, F. (1983). Neuronal production, migration, and differentiation in a vocal control nucleus of the adult female canary brain. Proc. Natl. Acad. Sci. U.S.A. 80, 2390-2394. doi: 10.1073/pnas.80.8.2390

Hamilton, A. (1901). The division of differentiated cells in the central nervous system of the white rat. J. Comp. Neurol. 11, 297-320. doi: 10.1002/cne.910110403

Hattiangady, B., Rao, M. S., and Shetty, A. K. (2004). Chronic temporal lobe epilepsy is associated with severely declined dentate neurogenesis in the adult hippocampus. Neurobiol. Dis. 17, 473-490. doi: 10.1016/j.nbd.2004.08.008

Hattiangady, B., and Shetty, A. K. (2008). Implications of decreased hippocampal neurogenesis in chronic temporal lobe epilepsy. Epilepsia 49 (Suppl. 5), 26-41. doi: 10.1111/j.1528-1167.2008.01635.x

Hoglinger, G. U., Rizk, P., Muriel, M. P., Duyckaerts, C., Oertel, W. H., Caille, I., et al. (2004). Dopamine depletion impairs precursor cell proliferation in Parkinson disease. Nat. Neurosci. 7, 726-735. doi: 10.1038/nn1265

Imayoshi, I., Sakamoto, M., Ohtsuka, T., Takao, K., Miyakawa, T., Yamaguchi, M., et al. (2008). Roles of continuous neurogenesis in the structural and functional integrity of the adult forebrain. Nat. Neurosci. 11, 1153-1161. doi: 10.1038/nn.2185

Imitola, J., Raddassi, K., Park, K. I., Mueller, F. J., Nieto, M., Teng, Y. D., et al. (2004) Directed migration of neural stem cells to sites of CNS injury by the stromal cellderived factor lalpha/CXC chemokine receptor 4 pathway. Proc. Natl. Acad. Sci. U.S.A. 101, 18117-18122. doi: 10.1073/pnas.0408258102

Irvin, D. K., Nakano, I., Paucar, A., and Kornblum, H. I. (2004). Patterns of Jagged1, Jagged2, Delta-like 1 and Delta-like 3 expression during late embryonic and postnatal brain development suggest multiple functional roles in progenitors and differentiated cells. J. Neurosci. Res. 75, 330-343. doi: 10.1002/jnr.10843

Jakubs, K., Bonde, S., Iosif, R. E., Ekdahl, C. T., Kokaia, Z., Kokaia, M., et al. (2008). Inflammation regulates functional integration of neurons born in adult brain. J. Neurosci. 28, 12477-12488. doi: 10.1523/JNEUROSCI.3240-08.2008

Ji, J. F., He, B. P., Dheen, S. T., and Tay, S. S. (2004). Expression of chemokine receptors CXCR4, CCR2, CCR5 and CX3CR1 in neural progenitor cells isolated from the subventricular zone of the adult rat brain. Neurosci. Lett. 355, 236-240. doi: 10.1016/j.neulet.2003.11.024

Jin, K., Minami, M., Lan, J. Q., Mao, X. O., Batteur, S., Simon, R. P., et al. (2001). Neurogenesis in dentate subgranular zone and rostral subventricular zone after focal cerebral ischaemia in the rat. Proc. Natl. Acad. Sci. U.S.A. 98, 4710-4715. doi: 10.1073/pnas.081011098

Jin, K., Wang, X., Xie, L., Mao, X. O., and Greenberg, D. A. (2010). Transgenic ablation of doublecortin-expressing cells suppresses adult neurogenesis and worsens stroke outcome in mice. Proc. Natl. Acad. Sci. U.S.A. 107, 7993-7998. doi: $10.1073 /$ pnas. 1000154107 
Kaba, H., Hayashi, Y., Higuchi, T., and Nakanishi, S. (1994). Induction of an olfactory memory by the activation of a metabotropic glutamate receptor. Science 265, 262-264. doi: 10.1126/science.8023145

Kageyama, R., Imayoshi, I., and Sakamoto, M. (2012). The role of neurogenesis in olfaction-dependent behaviors. Behav. Brain Res. 227, 459-463. doi: 10.1016/j.bbr.2011.04.038

Kazanis, I. (2009). The subependymal zone neurogenic niche: a beating heart in the centre of the brain: how plastic is adult neurogenesis? Opportunities for therapy and questions to be addressed. Brain 132, 2909-2921. doi: 10.1093/brain/awp237

Kempermann, G., Kuhn, H. G., and Gage, F. H. (1997). More hippocampal neurons in adult mice living in an enriched environment. Nature 386, 493-495. doi: 10.1038/386493a0

Kitamura, T., Saitoh, Y., Takashima, N., Murayama, A., Niibori, Y., Ageta, H., et al. (2009). Adult neurogenesis modulates the hippocampus-dependent period of associative fear memory. Cell 139, 814-827. doi: 10.1016/j.cell.2009. 10.020

Knoth, R., Singec, I., Ditter, M., Pantazis, G., Capetian, P., Meyer, R. P., et al. (2010). Murine features of neurogenesis in the human hippocampus across the lifespan from 0 to 100 years. PLoS ONE 5:e8809. doi: 10.1371/journal.pone.00 08809

Kokaia, Z., Martino, G., Schwartz, M., and Lindvall, O. (2012). Cross-talk between neural stem cells and immune cells: the key to better brain repair? Nat. Neurosci. 15, 1078-1087. doi: 10.1038/nn.3163

Kokoeva, M. V., Yin, H., and Flier, J. S. (2005). Neurogenesis in the hypothalamus of adult mice: potential role in energy balance. Science 310, 679-683. doi: $10.1126 /$ science. 1115360

Koos, T., and Tepper, J. M. (1999). Inhibitory control of neostriatal projection neurons by GABAergic interneurons. Nat. Neurosci. 2, 467-472. doi: 10.1038/8138

Kukekov, V. G., Laywell, E. D., Suslov, O., Davies, K., Scheffler, B., Thomas, L. B., et al. (1999). Multipotent stem/progenitor cells with similar properties arise from two neurogenic regions of adult human brain. Exp. Neurol. 156, 333-344. doi: 10.1006/exnr.1999.7028

Laterza, C., Merlini, A., De Feo, D., Ruffini, F., Menon, R., Onorati, M., et al. (2013). iPSC-derived neural precursors exert a neuroprotective role in immunemediated demyelination via the secretion of LIF. Nat. Commun. 4, 2597. doi: 10.1038/ncomms3597

Lazarini, F., Mouthon, M. A., Gheusi, G., De Chaumont, F., Olivo-Marin, J. C., Lamarque, S., et al. (2009). Cellular and behavioral effects of cranial irradiation of the subventricular zone in adult mice. PLoS ONE 4:e7017. doi: 10.1371/journal.pone.0007017

Lee, D. A., Bedont, J. L., Pak, T., Wang, H., Song, J., Miranda-Angulo, A., et al. (2012). Tanycytes of the hypothalamic median eminence form a diet-responsive neurogenic niche. Nat. Neurosci. 15, 700-702. doi: 10.1038/ nn.3079

Lee, S. T., Chu, K., Jung, K. H., Kim, S. J., Kim, D. H., Kang, K. M., et al. (2008). Anti-inflammatory mechanism of intravascular neural stem cell transplantation in haemorrhagic stroke. Brain 131, 616-629. doi: 10.1093/brain/ awm306

Leone, S., Mutti, C., Kazantsev, A., Sturlese, M., Moro, S., Cattaneo, E., et al. (2008). SAR and QSAR study on 2-aminothiazole derivatives, modulators of transcriptional repression in Huntington's disease. Bioorg. Med. Chem. 16, 5695-5703. doi: 10.1016/j.bmc.2008.03.067

Lois, C., and Alvarez-Buylla, A. (1994). Long-distance neuronal migration in the adult mammalian brain. Science 264, 1145-1148. doi: 10.1126/science.8178174

Lu, P., Jones, L. L., Snyder, E. Y., and Tuszynski, M. H. (2003). Neural stem cells constitutively secrete neurotrophic factors and promote extensive host axonal growth after spinal cord injury. Exp. Neurol. 181, 115-129. doi: 10.1016/S00144886(03)00037-2

Lu, Z., Elliott, M. R., Chen, Y., Walsh, J. T., Klibanov, A. L., Ravichandran, K. S., et al. (2011). Phagocytic activity of neuronal progenitors regulates adult neurogenesis. Nat. Cell Biol. 13, 1076-1083. doi: 10.1038/ncb2299

Mak, G. K., Enwere, E. K., Gregg, C., Pakarainen, T., Poutanen, M., Huhtaniemi, I., et al. (2007). Male pheromone-stimulated neurogenesis in the adult female brain: possible role in mating behavior. Nat. Neurosci. 10, 1003-1011. doi: 10.1038/nn 1928

Mak, G. K., and Weiss, S. (2010). Paternal recognition of adult offspring mediated by newly generated CNS neurons. Nat. Neurosci. 13, 753-758. doi: $10.1038 / \mathrm{nn} .2550$
Mandairon, N., Sacquet, J., Garcia, S., Ravel, N., Jourdan, F., and Didier, A. (2006). Neurogenic correlates of an olfactory discrimination task in the adult olfactory bulb. Eur. J. Neurosci. 24, 3578-3588. doi: 10.1111/j.1460-9568.2006. 05235.x

Marti-Fabregas, J., Romaguera-Ros, M., Gomez-Pinedo, U., Martinez-Ramirez, S., Jimenez-Xarrie, E., Marin, R., et al. (2010). Proliferation in the human ipsilateral subventricular zone after ischaemic stroke. Neurology 74, 357-365. doi: 10.1212/WNL.0b013e3181cbccec

Martino, G., and Pluchino, S. (2006). The therapeutic potential of neural stem cells. Nat. Rev. Neurosci. 7, 395-406. doi: 10.1038/nrn1908

Mathern, G. W., Leiphart, J. L., De Vera, A., Adelson, P. D., Seki, T., Neder, L., et al. (2002). Seizures decrease postnatal neurogenesis and granule cell development in the human fascia dentata. Epilepsia 43(Suppl. 5), 68-73. doi: 10.1046/j.15281157.43.s.5.28.x

Meletis, K., Barnabe-Heider, F., Carlen, M., Evergren, E., Tomilin, N., Shupliakov, O., et al. (2008). Spinal cord injury reveals multilineage differentiation of ependymal cells. PLoS Biol. 6:e182. doi: 10.1371/journal.pbio.0060182

Menn, B., Garcia-Verdugo, J. M., Yaschine, C., Gonzalez-Perez, O., Rowitch, D., and Alvarez-Buylla, A. (2006). Origin of oligodendrocytes in the subventricular zone of the adult brain. J. Neurosci. 26, 7907-7918. doi: 10.1523/JNEUROSCI.129906.2006

Ming, G. L., and Song, H. (2005). Adult neurogenesis in the mammalian central nervous system. Annu. Rev. Neurosci. 28, 223-250. doi: 10.1146/annurev.neuro.28.051804.101459

Mirzadeh, Z., Merkle, F. T., Soriano-Navarro, M., Garcia-Verdugo, J. M., and Alvarez-Buylla, A. (2008). Neural stem cells confer unique pinwheel architecture to the ventricular surface in neurogenic regions of the adult brain. Cell Stem Cell 3, 265-278. doi: 10.1016/j.stem.2008.07.004

Mohammad, M. G., Tsai, V. W., Ruitenberg, M. J., Hassanpour, M., Li, H., Hart, P. H., et al. (2014). Immune cell trafficking from the brain maintains CNS immune tolerance. J. Clin. Invest. 124, 1228-1241. doi: 10.1172/JCI71544

Monje, M. L., Toda, H., and Palmer, T. D. (2003). Inflammatory blockade restores adult hippocampal neurogenesis. Science 302, 1760-1765. doi: 10.1126/science. 1088417

Moreno, M. M., Linster, C., Escanilla, O., Sacquet, J., Didier, A., and Mandairon, N. (2009). Olfactory perceptual learning requires adult neurogenesis. Proc. Natl. Acad. Sci. U.S.A. 106, 17980-17985. doi: 10.1073/pnas.0907063106

Mosher, K. I., Andres, R. H., Fukuhara, T., Bieri, G., Hasegawa-Moriyama, M., He, Y., et al. (2012). Neural progenitor cells regulate microglia functions and activity. Nat. Neurosci. 15, 1485-1487. doi: 10.1038/nn.3233

Nait-Oumesmar, B., Decker, L., Lachapelle, F., Avellana-Adalid, V., Bachelin, C., and Baron-Van Evercooren, A. (1999). Progenitor cells of the adult mouse subventricular zone proliferate, migrate and differentiate into oligodendrocytes after demyelination. Eur. J. Neurosci. 11, 4357-4366. doi: 10.1046/j.14609568.1999.00873.x

Nottebohm, F. (1981). A brain for all seasons: cyclical anatomical changes in song control nuclei of the canary brain. Science 214, 1368-1370. doi: 10.1126/science.7313697

Ohab, J. J., Fleming, S., Blesch, A., and Carmichael, S. T. (2006). A neurovascular niche for neurogenesis after stroke. J. Neurosci. 26, 13007-13016. doi: 10.1523/JNEUROSCI.4323-06.2006

Palmer, T. D., Willhoite, A. R., and Gage, F. H. (2000). Vascular niche for adult hippocampal neurogenesis. J. Comp. Neurol. 425, 479-494. doi: 10.1002/10969861(20001002)425:4\%3C479::AID-CNE2\%3E3.0.CO;2-3

Parent, J. M., Von Dem Bussche, N., and Lowenstein, D. H. (2006). Prolonged seizures recruit caudal subventricular zone glial progenitors into the injured hippocampus. Hippocampus 16, 321-328. doi: 10.1002/hipo.20166

Platel, J. C., Dave, K. A., and Bordey, A. (2008). Control of neuroblast production and migration by converging GABA and glutamate signals in the postnatal forebrain. J. Physiol. 586, 3739-3743. doi: 10.1113/jphysiol.2008. 155325

Platel, J. C., Dave, K. A., Gordon, V., Lacar, B., Rubio, M. E., and Bordey, A. (2010). NMDA receptors activated by subventricular zone astrocytic glutamate are critical for neuroblast survival prior to entering a synaptic network. Neuron 65, 859-872. doi: 10.1016/j.neuron.2010.03.009

Pluchino, S., Muzio, L., Imitola, J., Deleidi, M., Alfaro-Cervello, C., Salani, G., et al. (2008). Persistent inflammation alters the function of the endogenous brain stem cell compartment. Brain 131, 2564-2578. doi: 10.1093/brain/ awn 198 
Pluchino, S., Quattrini, A., Brambilla, E., Gritti, A., Salani, G., Dina, G., et al. (2003). Injection of adult neurospheres induces recovery in a chronic model of multiple sclerosis. Nature 422, 688-694. doi: 10.1038/nature 01552

Pluchino, S., Zanotti, L., Rossi, B., Brambilla, E., Ottoboni, L., Salani, G., et al. (2005). Neurosphere-derived multipotent precursors promote neuroprotection by an immunomodulatory mechanism. Nature 436, 266-271. doi: 10.1038/nature03889

Ramon Y Cajal, S. (1913). Degeneration and Regeneration of the Nervous System. London: Oxford Univ. Press.

Rampon, C., Weiss, N., Deboux, C., Chaverot, N., Miller, F., Buchet, D., et al. (2008). Molecular mechanism of systemic delivery of neural precursor cells to the brain: assembly of brain endothelial apical cups and control of transmigration by CD44. Stem Cells 26, 1673-1682. doi: 10.1634/stemcells.2008-0122

Rappert, A., Bechmann, I., Pivneva, T., Mahlo, J., Biber, K., Nolte, C., et al. (2004). CXCR3-dependent microglial recruitment is essential for dendrite loss after brain lesion. J. Neurosci. 24, 8500-8509. doi: 10.1523/JNEUROSCI.245104.2004

Redmond, D. E. Jr., Bjugstad, K. B., Teng, Y. D., Ourednik, V., Ourednik, J., Wakeman, D. R., et al. (2007). Behavioral improvement in a primate Parkinson's model is associated with multiple homeostatic effects of human neural stem cells. Proc. Natl. Acad. Sci. U.S.A. 104, 12175-12180. doi: 10.1073/pnas.0704091104

Reynolds, B. A., and Weiss, S. (1992). Generation of neurons and astrocytes from isolated cells of the adult mammalian central nervous system. Science 255, 1707-1710. doi: 10.1126/science. 1553558

Riquelme, P. A., Drapeau, E., and Doetsch, F. (2008). Brain micro-ecologies: neural stem cell niches in the adult mammalian brain. Philos. Trans. R. Soc. Lond. B Biol. Sci. 363, 123-137. doi: 10.1098/rstb.2006.2016

Rotheneichner, P., Marschallinger, J., Couillard-Despres, S., and Aigner, L. (2013). Neurogenesis and neuronal regeneration in status epilepticus. Epilepsia 54(Suppl. 6), 40-42. doi: 10.1111/epi.12274

Ryu, J. K., Kim, J., Cho, S. J., Hatori, K., Nagai, A., Choi, H. B., et al. (2004). Proactive transplantation of human neural stem cells prevents degeneration of striatal neurons in a rat model of Huntington disease. Neurobiol. Dis. 16, 68-77. doi: 10.1016/j.nbd.2004.01.016

Sabelström, H., Stenudd, M., Reu, P., Dias, D. O., Elfineh, M., Zdunek, S., et al. (2013). Resident neural stem cells restrict tissue damage and neuronal loss after spinal cord injury in mice. Science 342, 637-640. doi: 10.1126/science.12 42576

Sahay, A., Scobie, K. N., Hill, A. S., O'carroll, C. M., Kheirbek, M. A., Burghardt, N. S., et al. (2011). Increasing adult hippocampal neurogenesis is sufficient to improve pattern separation. Nature 472, 466-470. doi: 10.1038/nature09817

Sakamoto, M., Imayoshi, I., Ohtsuka, T., Yamaguchi, M., Mori, K., and Kageyama, R. (2011). Continuous neurogenesis in the adult forebrain is required for innate olfactory responses. Proc. Natl. Acad. Sci. U.S.A. 108, 8479-8484. doi: 10.1073/pnas.1018782108

Sanai, N., Berger, M. S., Garcia-Verdugo, J. M., and Alvarez-Buylla, A. (2007). Comment on "Human neuroblasts migrate to the olfactory bulb via a lateral ventricular extension”. Science 318, 393. doi: 10.1126/science.1145011

Sanai, N., Nguyen, T., Ihrie, R. A., Mirzadeh, Z., Tsai, H. H., Wong, M., et al. (2011). Corridors of migrating neurons in the human brain and their decline during infancy. Nature 478, 382-386. doi: 10.1038/nature10487

Sanai, N., Tramontin, A. D., Quinones-Hinojosa, A., Barbaro, N. M., Gupta, N., Kunwar, S., et al. (2004). Unique astrocyte ribbon in adult human brain contains neural stem cells but lacks chain migration. Nature 427, 740-744. doi: 10.1038/nature02301

Sawamoto, K., Wichterle, H., Gonzalez-Perez, O., Cholfin, J. A., Yamada, M., Spassky, N., et al. (2006). New neurons follow the flow of cerebrospinal fluid in the adult brain. Science 311, 629-632. doi: 10.1126/science.1119133

Seifert, T., Bauer, J., Weissert, R., Fazekas, F., and Storch, M. K. (2005). Differential expression of sonic hedgehog immunoreactivity during lesion evolution in autoimmune encephalomyelitis. J. Neuropathol. Exp. Neurol. 64, 404-411.

Shingo, T., Gregg, C., Enwere, E., Fujikawa, H., Hassam, R., Geary, C., et al. (2003). Pregnancy-stimulated neurogenesis in the adult female forebrain mediated by prolactin. Science 299, 117-120. doi: 10.1126/science.1076647

Shors, T. J., Townsend, D. A., Zhao, M., Kozorovitskiy, Y., and Gould, E. (2002). Neurogenesis may relate to some but not all types of hippocampal-dependent learning. Hippocampus 12, 578-584. doi: 10.1002/hipo.10103
Sierra, A., Encinas, J. M., Deudero, J. J., Chancey, J. H., Enikolopov, G., OverstreetWadiche, L. S., et al. (2010). Microglia shape adult hippocampal neurogenesis through apoptosis-coupled phagocytosis. Cell Stem Cell 7, 483-495. doi: 10.1016/j.stem.2010.08.014

Singer, B. H., Jutkiewicz, E. M., Fuller, C. L., Lichtenwalner, R. J., Zhang, H., Velander, A. J., et al. (2009). Conditional ablation and recovery of forebrain neurogenesis in the mouse. J. Comp. Neurol. 514, 567-582. doi: 10.1002/cne.22052

Smart, I. (1961). The subependymal layer of the mouse brain and its cell production as shown by autography after [H3]-thymidine injection. J. Comp. Neurol. 116, 325-327. doi: 10.1002/cne.901160306

Snyder, J. S., Hong, N. S., McDonald, R. J., and Wojtowicz, J. M. (2005). A role for adult neurogenesis in spatial long-term memory. Neuroscience 130, 843-852. doi: 10.1016/j.neuroscience.2004.10.009

Snyder, J. S., Soumier, A., Brewer, M., Pickel, J., and Cameron, H. A. (2011). Adult hippocampal neurogenesis buffers stress responses and depressive behaviour. Nature 476, 458-461. doi: 10.1038/nature10287

Spalding, K. L., Bergmann, O., Alkass, K., Bernard, S., Salehpour, M., Huttner, H. B., et al. (2013). Dynamics of hippocampal neurogenesis in adult humans. Cell 153, 1219-1227. doi: 10.1016/j.cell.2013.05.002

Stock, K., Kumar, J., Synowitz, M., Petrosino, S., Imperatore, R., Smith, E. S., et al. (2012). Neural precursor cells induce cell death of high-grade astrocytomas through stimulation of TRPV1. Nat. Med. 18, 1232-1238. doi: 10.1038/ nm.2827

Sun, C., Sun, H., Wu, S., Lee, C. C., Akamatsu, Y., Wang, R. K., et al. (2013). Conditional ablation of neuroprogenitor cells in adult mice impedes recovery of poststroke cognitive function and reduces synaptic connectivity in the perforant pathway. J. Neurosci. 33, 17314-17325. doi: 10.1523/JNEUROSCI.212913.2013

Tavazoie, M., Van Der Veken, L., Silva-Vargas, V., Louissaint, M., Colonna, L., Zaidi, B., et al. (2008). A specialized vascular niche for adult neural stem cells. Cell Stem Cell 3, 279-288. doi: 10.1016/j.stem.2008.07.025

Tello, J. F. (1907). La Regeneration dans les Voies Optiques. Madrid: Trab Lab Invest Biol Univ Madr.

Teng, H., Zhang, Z. G., Wang, L., Zhang, R. L., Zhang, L., Morris, D., et al. (2008). Coupling of angiogenesis and neurogenesis in cultured endothelial cells and neural progenitor cells after stroke. J. Cereb. Blood Flow Metab. 28, 764-771. doi: $10.1038 /$ sj.jcbfm. 9600573

Teng, Y. D., Lavik, E. B., Qu, X., Park, K. I., Ourednik, J., Zurakowski, D., et al. (2002). Functional recovery following traumatic spinal cord injury mediated by a unique polymer scaffold seeded with neural stem cells. Proc. Natl. Acad. Sci. U.S.A. 99, 3024-3029. doi: 10.1073/pnas.052678899

Thored, P., Arvidsson, A., Cacci, E., Ahlenius, H., Kallur, T., Darsalia, V., et al. (2006). Persistent production of neurons from adult brain stem cells during recovery after stroke. Stem Cells 24, 739-747. doi: 10.1634/stemcells. 2005-0281

Thored, P., Heldmann, U., Gomes-Leal, W., Gisler, R., Darsalia, V., Taneera, J., et al. (2009). Long-term accumulation of microglia with proneurogenic phenotype concomitant with persistent neurogenesis in adult subventricular zone after stroke. Glia 57, 835-849. doi: 10.1002/glia.20810

Thored, P., Wood, J., Arvidsson, A., Cammenga, J., Kokaia, Z., and Lindvall, O. (2007). Long-term neuroblast migration along blood vessels in an area with transient angiogenesis and increased vascularization after stroke. Stroke 38, 3032-3039. doi: 10.1161/STROKEAHA.107.488445

Tong, C. K., Chen, J., Cebrian-Silla, A., Mirzadeh, Z., Obernier, K., Guinto, C. D., et al. (2014). Axonal control of the adult neural stem cell niche. Cell Stem Cell 14, 500-511. doi: 10.1016/j.stem.2014.01.014

Villeda, S. A., Luo, J., Mosher, K. I., Zou, B., Britschgi, M., Bieri, G., et al. (2011). The ageing systemic milieu negatively regulates neurogenesis and cognitive function. Nature 477, 90-94. doi: 10.1038/nature10357

Wang, X., Mao, X., Xie, L., Sun, F., Greenberg, D. A., and Jin, K. (2012). Conditional depletion of neurogenesis inhibits long-term recovery after experimental stroke in mice. PLoS ONE 7:e38932. doi: 10.1371/journal.pone.00 38932

Willshaw, D. J., and Buckingham, J. T. (1990). An assessment of Marr's theory of the hippocampus as a temporary memory store. Philos. Trans. R. Soc. Lond. B Biol. Sci. 329, 205-215. doi: 10.1098/rstb.1990.0165

Young, S. Z., Taylor, M. M., and Bordey, A. (2011). Neurotransmitters couple brain activity to subventricular zone neurogenesis. Eur. J. Neurosci. 33, 1123-1132. doi: 10.1111/j.1460-9568.2011.07611.x 
Zhang, Z. G., and Chopp, M. (2009). Neurorestorative therapies for stroke: underlying mechanisms and translation to the clinic. Lancet Neurol. 8, 491-500. doi: 10.1016/S1474-4422(09)70061-4

Zhao, C., Deng, W., and Gage, F. H. (2008). Mechanisms and functional implications of adult neurogenesis. Cell 132, 645-660. doi: 10.1016/j.cell.2008.01.033

Ziv, Y., Avidan, H., Pluchino, S., Martino, G., and Schwartz, M. (2006). Synergy between immune cells and adult neural stem/progenitor cells promotes functional recovery from spinal cord injury. Proc. Natl. Acad. Sci. U.S.A. 103, 13174-13179. doi: 10.1073/pnas.0603747103

Conflict of Interest Statement: The authors declare that the research was conducted in the absence of any commercial or financial relationships that could be construed as a potential conflict of interest.
Received: 19 February 2014; accepted: 09 April 2014; published online: 29 April 2014. Citation: Butti E, Cusimano M, Bacigaluppi M and Martino G (2014) Neurogenic and non-neurogenic functions of endogenous neural stem cells. Front. Neurosci. 8:92. doi: 10.3389/fnins.2014.00092

This article was submitted to Neurogenesis, a section of the journal Frontiers in Neuroscience.

Copyright (c) 2014 Butti, Cusimano, Bacigaluppi and Martino. This is an openaccess article distributed under the terms of the Creative Commons Attribution License (CC BY). The use, distribution or reproduction in other forums is permitted, provided the original author(s) or licensor are credited and that the original publication in this journal is cited, in accordance with accepted academic practice. No use, distribution or reproduction is permitted which does not comply with these terms. 